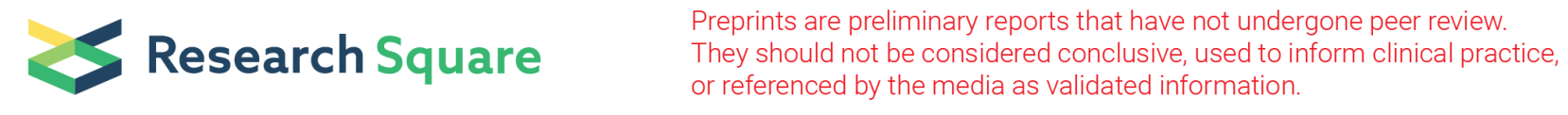

\title{
Online Food Delivery Services Among Young Adults in Depok: Factors Affecting the Frequency of Online Food Ordering and Consumption of High- risk Food
}

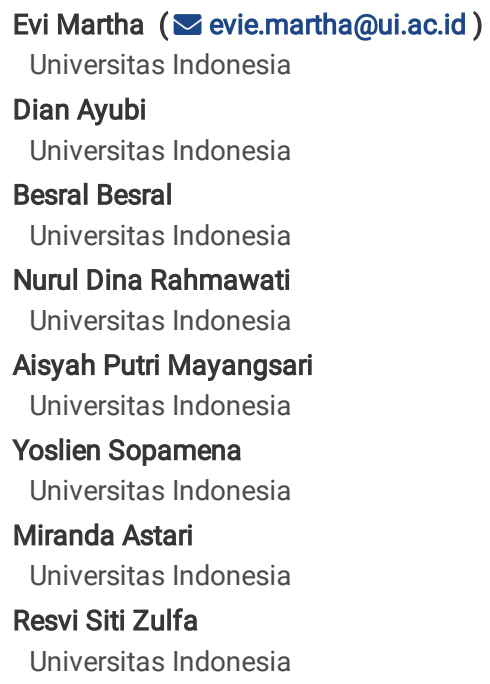




\section{Abstract}

Background

The increasing desire of the community towards fulfilling the practical needs of life is currently accommodated by the rapid development of communication technology in the last five years in Indonesia. One example is the emergence of various food delivery applications. This will affect the pattern of daily food consumption in the community. Therefore, this study determined the personal and socio-environmental factors that influence the frequency of online food ordering (OFO) behavior and also high-risk food consumption through online food delivery services (OFDS) among young adults in Depok City.

Methods

This research was a cross-sectional study conducted with 686 participants of young adults aged 20-39 years that lived in Depok City, West Java Province, Indonesia, for minimal the last six months. They were administered a questionnaire through Alchemer, formerly SurveyGizmo. Descriptive statistics were employed for all variables measured. A T-test and a Chi-square test were conducted to determine the factors influencing the OFO frequency and high-risk food consumption through OFDS. Predictor variables were generated using multi-logistic regression models. The predictor for the frequency of OFO behavior was satisfaction toward OFDS ( $B=3.3 ; \mathrm{Cl}$ : 2.4-4.7; $p$-value $=0.000)$, while those for high-risk food consumption were personal and socio-environmental factors $(B$ $=1.8 ; \mathrm{Cl}: 1.3-2.5 ; \mathrm{p}$-value $=0.001$ and $B=1.7 ; \mathrm{Cl}: 1.2-2.4 ; \mathrm{p}$-value $=0.001$, respectively $)$.

Results

The personal and socio-environmental factors related to the frequency of OFO behavior were attitudes toward risk, benefit, barriers, features of OFDS, satisfaction with OFDS, socio-environmental influence, perception about OFDS, and online food preference. Furthermore, the factors associated with high-risk food consumption through OFDS were attitudes toward benefit, features, satisfaction with OFDS, socio-environmental influence, perception about OFDS, online food preference, and knowledge of OFDS.

Conclusions

Satisfaction, social environment, and food preference play essential roles in OFDS. The findings demonstrated the urgency of conducting further studies to elaborate on the association of OFDS with non-communicable diseases.

\section{Background}

The development of communication technology, particularly sophisticated applications (apps) supported by smartphones, has affected numerous ecommerce transactions, including online food delivery services (OFDS).(1) The community, especially the millennial generation, prefers to use mobile apps to order food online from their preferred restaurant and get food delivered at their doorstep.(2,3) Through an app downloaded on their smartphone, customers can easily order any cuisine without having to leave their house.(4)

OFDS is a process of placing food orders from local restaurants or food cooperatives through website pages or mobile apps and then getting them delivered to their doorstep.(5) The recent development of the Internet has facilitated online food ordering (OFO) and delivery through marketplace apps [platforms that offer access to multiple restaurants and handle delivery goods (e.g., GoFood and GrabFood)].(6) The real-time connectivity of food delivery apps on mobile devices provides busy users with high speed and convenience advantages. In addition, Lee et al. ${ }^{7}$ found that the customer's habit of using OFDS significantly influences their intention of using OFDS regularly. It is also affected by how the OFDS performs and the social environment. ${ }^{7}$ Talabpetch(8) showed that an online food providers' convenience has resulted in most businesswomen in Thailand availing these services frequently.

According to a survey conducted by the Nielsen Research Institute, $95 \%$ of Indonesians enjoy ready-to-eat types of food,(9) of which $58 \%$ order food online through food delivery apps installed on their mobile phones. The survey was conducted on 1000 respondents (aged 18-45 years), spread across the following major cities in Indonesia: Jakarta-Bogor-Depok-Tangerang-Bekasi, Semarang, Surabaya, Makassar, and Medan. The data on the use of delivery services for the last three months were collected and revealed that $41 \%$ of the respondents ordered food through OFDS, whereas $85 \%$ ordered through GoFood, GrabFood, and similar applications.(9)

Despite the opportunities generated by this commerce, OFDS has also played a significant role in decreased physical activity of people, as well as excess calorie intake and adverse health outcomes.(10) These services have also affected the eating behavior of people. Healthy eating behavior is an essential determinant of a person's overall health.(11) This dietary behavior is complex and influenced by many factors, such as personal, social, cultural, environmental, and economic factors.(12) Because the dietary pattern is a significant risk factor for developing obesity, diabetes, and cardiovascular diseases, understanding the particular behavior and motivational factors that encourage selecting and purchasing a particular food item is essential to tackle the epidemic of those non-communicable diseases (NCD).(13,14) Given these circumstances, intervention is required to create a food environment that establishes healthy eating behavior.(15)

The present study adopts the social cognitive theory, developed by Bandura, as its framework. This theory hypothesizes that individual behavior results from a constant interaction between the external environment and internal psychosocial characteristics (in terms of cognitive, affective, and biological factors).

(16) The present study aims to examine the effect of this interaction on OFO frequency and high-risk food consumption through OFDS among young adults in Depok City, West Java.

\section{Methods}




\section{Study design and samples}

The study participants met the following inclusion criteria: young adults aged 20-39 years and residents of Depok city, or living in Depok for the last six months. Based on the statistical calculation performed using two-sided hypothesis testing for a single population proportion, the sample was 320 through 620 respondents. Ten percent of the minimal sample size $(\mathrm{N}=32)$ was used for pre-testing the questionnaire and measuring the validity and reliability of the instruments used.

\section{Phase 1: Development of scales and items}

A set of quantitative and qualitative procedures were conducted to develop the scales. In addition, a literature review was conducted to examine the content and psychometric properties of similar social cognitive constructs related to the frequency of OFO behavior and high-risk food consumption through OFDS. Nutrition specialists were asked to analyze and review the preliminary questions. A total of 124 items covering 15 sociodemographic topics were generated during the review process. The following were used as dependent variables: 1) 24 items to measure the OFO frequency, which was categorized as more frequent and less frequent, and 2) 11 items to measure the consumption of a high-sugar and high-fat type of food items ordered through OFDS. The independent variables were divided into personal and environmental factors. Personal/cognitive factors are knowledge about OFDS practices; knowledge about nutrition content; and perception, attitude, and respondents' food preference. Furthermore, the environmental factors are the socio-environmental factors that influenced young adults' decision to use OFDS.

\section{Scale construction}

\section{Personal factor}

For the 16 items of instruments, the respondents were asked to rate their knowledge regarding food nutrition (19 items) and OFO practice (4 items), where each correct option was assigned one point. The respondents were asked to rate their perception (6 items) regarding OFD practices on a four-point Likert-type scale ( 1 = strongly disagree; 4 = strongly agree). For the subscale, the participants' attitudes toward OFDS were examined, which included attitudes toward risk (3 items), benefit ( 5 items), barriers (5 items), features ( 3 items), and satisfaction with OFDS (4 items), and were rated through a four-point Likert-type scale. For the food preferences (total 17 items), the participants were asked to rate the provided cuisines on a six-point Likert-type scale (1 = dislike a lot; 2 = dislike; 3 = neither likes nor dislikes; 4 = likes; 5 = likes a lot; 6 = can't be determined).

\section{Socio-environmental factors}

Eight socio-environmental items were rated on a four-point Likert-type scale ( 1 = strongly disagree; 4 = agree) to analyze the food eating behavior of young adults. We used the terms family (e.g., parents and siblings), friends, influencer (e.g., artist and celebrity), advertisement, availability of traditional or modern market, availability of food's store, availability of drive through food corner, and availability of online food stores in neighborhood to trigger participants to assess the socio-environmental factors around them that might affect their food eating behavior.

\section{Frequency of OFO behavior and high-risk food consumption through OFDS}

To assess the frequency of OFO behavior of the participants, we employed a questionnaire comprising eight questions. The participants were asked to indicate their OFO frequency under the following four categories: 1-3 times/month, 4-6 times/month, 7-10 times/month, and more than 10 times/month. For further analysis, these categories were coded as numbers 1-4, where the highest number indicated the highest OFO frequency. Meanwhile, for high-risk food consumption through OFDS, we asked the participants to rate the food groups, namely fast food, vegetables, fruits, noodles, chicken, fried rice, and processed bread, as $0=$ never, $1=$ somewhat, and $2=$ most.

\section{Content validation, reliability, criterion, and construct validity}

Validity and reliability tests were conducted with 32 participants, initiated through cognitive interviews conducted by five nutrition experts and five public health specialists in health communication for content validity. The objective was to gain language and nutrition interpretation through their judgment. We obtained minor comments and revised them. Next, quantitative testing was performed with 32 participants through an online link distributed using Alchemer, formerly called SurveyGizmo. The objective was to determine the reliability and acceptability of the questionnaire. The internal reliability of the participants was assessed using Cronbach's alpha coefficient, which obtained a very good score of 0.71 .

\section{Phase 2: Data collection}

A cross-sectional study was conducted over three weeks between October and November 2020 in Depok City. The questionnaire was filled out by 686 participants-which were recruited through an electronic chat and social media, based on comprehensive sampling methods, to canvass a known group of participants. The questionnaire was administered through a registered online survey platform named Alchemer, formerly called SurveyGizmo. Using SPSS version 22, descriptive statistics were employed to examine all used variables, followed by a T-test and a Chi-square test conducted to analyze the significance of each variable against OFO frequency behavior and high-risk food consumption through OFDS. Then, each variable was subjected to multi-logistic regression to assess their corresponding predictable factors. This study obtained ethical approval from The Research and Community Engagement Ethical Committee of Faculty of Public Health Universitas Indonesia number 597/UN2.F10.D11/PPM/00.02/2020. This study was conducted following the Declaration of Helsinki, including providing informed consent from all participants and ensured that their anonymity was maintained.

\section{Results}


Table 1 lists the sociodemographic characteristics of the participants. The link survey was filled out by 686 participants, of which $79.4 \%$ were females, aged 20-29 years (63.1\%). In addition, most respondents were unmarried (52.5\%), 68.1\% had higher education (graduate from college or university), and $41.7 \%$ were employees.

Table 1 Sociodemographic characteristics $(\mathrm{N}=686)$

\begin{tabular}{|c|c|c|}
\hline Characteristics & $\mathbf{N}$ & $\%$ \\
\hline \multicolumn{3}{|l|}{ Gender } \\
\hline Male & 141 & 20.6 \\
\hline Female & 545 & 79.4 \\
\hline \multicolumn{3}{|l|}{ Age group } \\
\hline $20-29$ & 433 & 63.1 \\
\hline $30-39$ & 253 & 36.9 \\
\hline \multicolumn{3}{|l|}{ Employment } \\
\hline Student & 230 & 33.6 \\
\hline Employee & 286 & 41.7 \\
\hline Unemployed/other & 170 & 24.7 \\
\hline Marital status & - & \\
\hline Married & 326 & 47.5 \\
\hline Unmarried & 360 & 52.5 \\
\hline Number of ordering usually in a month & - & - \\
\hline $1-3$ times & 308 & 45.0 \\
\hline $4-6$ times & 198 & 28.9 \\
\hline$>7$ times & 180 & 26.2 \\
\hline \multicolumn{3}{|l|}{ Last education status } \\
\hline Elementary and Junior School & 6 & 0.8 \\
\hline High School & 207 & 30.2 \\
\hline College/University & 472 & 68.1 \\
\hline
\end{tabular}

\section{Distribution of respondents by type of food ordered}

Table 2 compares the frequencies of ordering various food items and beverages. Within the last month, the most frequently ordered food items and beverages were fast food (35.1\%), followed by chicken dishes (33.9\%), bubble tea (24.2\%), coffee (23.0\%), and sweet cakes (22.6\%). Meanwhile, sweet cake (59.3\%), fast food $(59.1 \%)$, and bubble tea (57.0\%) were predominantly ordered more than a month ago. In contrast, fruits were on the minor list of orders, as most participants $(45.2 \%)$ never ordered them.

Table 2 Distribution of type of food ordered by respondents $(N=686)$

\begin{tabular}{|llll|}
\hline Type of Food Ordered & Never & \multicolumn{2}{l|}{ Yes } \\
\cline { 3 - 4 } & & More than a month ago & Within a month \\
\cline { 2 - 4 } & $\mathbf{n}(\%)$ & $\mathbf{n}(\%)$ & $\mathbf{n}(\%)$ \\
\hline Bubble tea & $129(18.8)$ & $391(57.0)$ & $166(24.2)$ \\
Coffee Drink & $223(32.6)$ & $305(44.4)$ & $158(23.0)$ \\
Fast Food & $39(5.7)$ & $406(59.1)$ & $241(35.1)$ \\
Chicken dishes & $73(10.6)$ & $381(55.5)$ & $232(33.9)$ \\
Rice mix & $176(25.7)$ & $385(56.1)$ & $125(18.2)$ \\
Sweet cakes & $124(18.1)$ & $407(59.3)$ & $155(22.6)$ \\
Noodles & $184(26.9)$ & $370(53.9)$ & $132(19.2)$ \\
Fruits & $310(45.2)$ & $288(42.0)$ & $88(12.8)$ \\
\hline
\end{tabular}

Frequency of OFO behavior, high-risk food consumption through OFDS, and personal and socio-environmental factors 
The results of a bivariate analysis (Table 3) conducted in this study indicated significant persistent results between the attitudes toward benefit, food preference, satisfaction toward OFO, and socio-environmental influence on the frequency of OFO behavior and high-risk food consumption through OFDS. Each independent factor was treated as a composite score. Then, knowledge about OFDS and nutrition content and other independent variables were then classified as low (< mean score) and sufficient ( $\geq$ mean scores of 62 and 45 , respectively; otherwise, low). Attitudes toward risk, benefit, barriers, and features of OFDS were classified as positive ( $\geq$ mean scores of $71,77,68$, and 79 , respectively; otherwise, negative) and positive (=mean score). Meanwhile, satisfaction using OFDS, socio-environmental influences, perception toward OFDS, and food preference were the factors classified as positive ( $\geq$ mean scores of $72,58,72$, and 75, respectively; otherwise, negative). An increased positive attitude toward the benefit of using OFDS increased the likelihood of the participants consuming high-risk foods by almost two times compared to the times before the introduction of these services (OR $1.89,95 \% \mathrm{Cl}$ : $1.37-2.60)$.

Similarly, an improved perception about OFDS increased the likelihood of the participants consuming high-risk food by approximately 1.5 times (OR $1.41,95 \%$ Cl: 1.03-1.95). In addition, higher preference for high-risk foods, satisfaction toward OFO, and socio-environmental effects were related to increased consumption of high-risk food (OR 2.14, 95\% Cl: 1.57-2.93; OR 1.86, 95\% Cl: 1.36-2.54; and OR 1.97, 95\% Cl: 1.44- 2.70, respectively). The risk of using OFO varied from approximately 1.5 to more than four times. Interestingly, the lower attitudes of risk and barriers toward OFDS were only related to increased OFO frequency and unhealthy food consumption. At the same time, participants with better knowledge about OFDS tended to exhibit higher unhealthy food consumption (OR 1.43, 95\% Cl: 1.05-1.95).

Table 3 Bivariate analysis on the frequency of order and high-risk food consumption through OFDS (N=686) 


\begin{tabular}{|c|c|c|c|c|c|c|c|c|}
\hline \multirow{3}{*}{ Variables } & \multicolumn{4}{|c|}{ Frequency of Order } & \multicolumn{4}{|c|}{ High-Risk Food Consumption through OFDS } \\
\hline & Less & More & OR $95 \% \mathrm{Cl}$ & P-value & $\begin{array}{l}\text { Lower or } \\
\text { Similar }\end{array}$ & Higher & OR $95 \% \mathrm{Cl}$ & P-value \\
\hline & $\mathrm{n}(\%)$ & $\mathrm{n}(\%)$ & & & n (\%) & $\mathrm{n}(\%)$ & & \\
\hline All $(N=686)$ & $308(45.0)$ & $\begin{array}{l}377 \\
(55.0)\end{array}$ & & & $271(39.5)$ & $\begin{array}{l}414 \\
(60.5)\end{array}$ & & \\
\hline Knowledge about nutrition & & & 1.20 & 0.241 & & & 0.87 & 0.384 \\
\hline Low $(<62)$ & $130(47.8)$ & $\begin{array}{l}142 \\
(52.2)\end{array}$ & $(0.88-1.63)$ & & $102(37.5)$ & $\begin{array}{l}170 \\
(62.5)\end{array}$ & $\begin{array}{l}(0.64- \\
1.19)\end{array}$ & \\
\hline High ( $\geq 62)$ & $179(43.2)$ & $\begin{array}{l}235 \\
(56.8)\end{array}$ & & & $169(40.8)$ & $\begin{array}{l}245 \\
(59.2)\end{array}$ & & \\
\hline Attitude on risk of using OFDS & & & 0.72 & $0.032^{*}$ & & & 0.90 & 0.516 \\
\hline Negative $(<71)$ & $155(41.3)$ & $\begin{array}{l}220 \\
(58.7)\end{array}$ & $\begin{array}{l}(0.53- \\
0.97)\end{array}$ & & $144(38.4)$ & $\begin{array}{l}231 \\
(61.6)\end{array}$ & $\begin{array}{l}(0.66- \\
1.23)\end{array}$ & \\
\hline Positive ( $\geq 71$ ) & $154(49.5)$ & $\begin{array}{l}157 \\
(50.5)\end{array}$ & & & $127(40.8)$ & $\begin{array}{l}184 \\
(59.2)\end{array}$ & & \\
\hline Attitude on benefit of using OFDS & & & 1.96 & $<0.0001 * \star \star$ & & & 1.89 & $<0.0001^{\star * *}$ \\
\hline Negative $(<77)$ & $210(51.7)$ & $\begin{array}{l}196 \\
(48.3)\end{array}$ & $\begin{array}{l}(1.43- \\
2.68)\end{array}$ & & $185(45.6)$ & $\begin{array}{l}221 \\
(54.4)\end{array}$ & $\begin{array}{l}(1.37- \\
2.60)\end{array}$ & \\
\hline Positive ( $\geq 77$ ) & $99(35.4)$ & $\begin{array}{l}181 \\
(64.6)\end{array}$ & & & $86(30.8)$ & $\begin{array}{l}193 \\
(69.2)\end{array}$ & & \\
\hline Attitude on barriers of using OFDS & & & 1.41 & $0.026^{*}$ & & & 1.03 & 0.857 \\
\hline Low $(<68)$ & $174(49.2)$ & $\begin{array}{l}180 \\
(50.8)\end{array}$ & $\begin{array}{l}(1.04- \\
1.91)\end{array}$ & & $141(39.8)$ & $\begin{array}{l}213 \\
(60.2)\end{array}$ & $\begin{array}{l}(0.76- \\
1.40)\end{array}$ & \\
\hline $\operatorname{High}(\geq 68)$ & $135(40.7)$ & $\begin{array}{l}197 \\
(59.3)\end{array}$ & & & $130(39.2)$ & $\begin{array}{l}202 \\
(60.8)\end{array}$ & & \\
\hline Attitude towards features OFDS & & & 1.45 & $0.016^{*}$ & & & & $0.001^{\star \star}$ \\
\hline Negative $(<79)$ & & & $(1.07-$ & & & & 1.69 & \\
\hline & $189(49.1)$ & $\begin{array}{l}196 \\
(50.9)\end{array}$ & & & $173(44.9)$ & $\begin{array}{l}212 \\
(55.1)\end{array}$ & $(1.24-2.3)$ & \\
\hline Positive ( $\geq 79)$ & $120(39.9)$ & $\begin{array}{l}181 \\
(60.1)\end{array}$ & & & $98(32.6)$ & $\begin{array}{l}203 \\
(67.4)\end{array}$ & & \\
\hline Satisfaction of using OFDS & & & 3.83 & $<0.0001 \star \star \star$ & & & 1.86 & $<0.0001^{\star \star *}$ \\
\hline Satisfied $(<72)$ & $212(60.7)$ & $\begin{array}{l}137 \\
(39.3)\end{array}$ & $\begin{array}{l}(2.78- \\
5.27)\end{array}$ & & $163(46.7)$ & $\begin{array}{l}186 \\
(53.3)\end{array}$ & $\begin{array}{l}(1.36- \\
2.54)\end{array}$ & \\
\hline Unsatisfied ( $\geq 72)$ & $97(28.8)$ & $\begin{array}{l}240 \\
(71.2)\end{array}$ & & & $108(32.0)$ & $\begin{array}{l}229 \\
(68.0)\end{array}$ & & \\
\hline Social and environmental influence & & & 1.42 & $0.024^{*}$ & & & 1.97 & $<0.0001 * \star \star *$ \\
\hline Low $(<58)$ & $141(50.2)$ & $\begin{array}{l}140 \\
(49.8)\end{array}$ & $\begin{array}{l}(1.05- \\
1.93)\end{array}$ & & $138(49.1)$ & $\begin{array}{l}143 \\
(50.9)\end{array}$ & $\begin{array}{l}(1.44- \\
2.70)\end{array}$ & \\
\hline High $(\geq 58)$ & $168(41.5)$ & $\begin{array}{l}237 \\
(58.5)\end{array}$ & & & $133(32.8)$ & $\begin{array}{l}272 \\
(67.2)\end{array}$ & & \\
\hline Perception about OFDS & & & 1.61 & $0.003^{\star \star}$ & & & 1.41 & $0.033^{*}$ \\
\hline Negative $(<72)$ & $209(49.5)$ & $\begin{array}{l}213 \\
(50.5)\end{array}$ & $\begin{array}{l}(1.18- \\
2.20)\end{array}$ & & $180(42.7)$ & $\begin{array}{l}242 \\
(57.3)\end{array}$ & $\begin{array}{l}(1.03- \\
1.95)\end{array}$ & \\
\hline Positive ( $\geq 72$ ) & $100(37.9)$ & $\begin{array}{l}164 \\
(62.1)\end{array}$ & & & $91(34.5)$ & $\begin{array}{l}173 \\
(65.5)\end{array}$ & & \\
\hline Preference of online food choices & & & 1.56 & $0.004 * \star$ & & & 2.14 & $<0.0001 * * *$ \\
\hline Low $(<75)$ & $157(51.1)$ & $\begin{array}{l}150 \\
(48.9)\end{array}$ & $\begin{array}{l}(1.15- \\
2.12)\end{array}$ & & $152(49.5)$ & $\begin{array}{l}155 \\
(50.5)\end{array}$ & $\begin{array}{l}(1.57- \\
2.93)\end{array}$ & \\
\hline High ( $\geq 75)$ & $152(40.1)$ & $\begin{array}{l}227 \\
(59.9)\end{array}$ & & & $119(31.4)$ & $\begin{array}{l}260 \\
(68.6)\end{array}$ & & \\
\hline
\end{tabular}




\begin{tabular}{|c|c|c|c|c|c|c|c|c|}
\hline \multirow{3}{*}{ Variables } & \multicolumn{4}{|c|}{ Frequency of Order } & \multicolumn{4}{|c|}{ High-Risk Food Consumption through OFDS } \\
\hline & Less & More & OR $95 \% \mathrm{Cl}$ & P-value & $\begin{array}{l}\text { Lower or } \\
\text { Similar }\end{array}$ & Higher & OR $95 \% \mathrm{Cl}$ & P-value \\
\hline & $\mathrm{n}(\%)$ & n (\%) & & & $\mathrm{n}(\%)$ & $\mathrm{n}(\%)$ & & \\
\hline Knowledge about OFDS & & & 1.29 & 0.101 & & & 1.43 & $0.023^{*}$ \\
\hline Low $(<45)$ & $180(47.9)$ & $\begin{array}{l}196 \\
(52.1)\end{array}$ & $\begin{array}{l}(0.95- \\
1.75)\end{array}$ & & $163(43.4)$ & $\begin{array}{l}213 \\
(56.6)\end{array}$ & $\begin{array}{l}(1.05- \\
1.95)\end{array}$ & \\
\hline Sufficient ( $\geq 45$ ) & $129(41.6)$ & $\begin{array}{l}181 \\
(58.4)\end{array}$ & & & $108(34.8)$ & $\begin{array}{l}202 \\
(65.2)\end{array}$ & & \\
\hline
\end{tabular}

*p-value $<0.05 ; * *$ p-value $<0.01 ; * \star *$ p-value $<0.001$

\section{Relations among frequency of OFO behavior, high-risk food consumption, and personal and socio-environmental factors}

The relations among all factors related to the frequency of OFO behavior and high-risk food consumption through OFDS were analyzed using a multi-logistic regression model (Table 4). After adjusting for the covariates, the participants with high satisfaction with using OFDS ( $\beta=3.3$; $95 \% \mathrm{Cl}$ : $2.4-4.7)$ exhibited a significantly higher OFO frequency than those who did not. The participants who were influenced by socio-environmental factors ( $B=1.8 ; 95 \% \mathrm{Cl}$ : $1.3-2.5)$ and had a high preference for using ODFS ( $B=1.7 ; 95 \% \mathrm{Cl}$ : $1.2-2.4)$ exhibited significantly increased high-risk food consumption through OFDS than those who did not.

Table 4 Multiple logistic regression of frequency of OFO behavior and high-risk food consumption through OFDS (N=686)

Frequency of OFO Behavior

High-risk food consumption through OFDS

\begin{tabular}{lllllll}
\hline Variable & Sig. & Exp(B) & $\mathbf{9 5 \%} \mathbf{C l}$ & Sig. & Exp(B) & $95 \%$ Cl \\
\hline Knowledge about nutrition & 0.323 & 1.2 & $0.8-1.7$ & 0.314 & 0.8 & $0.6-1.2$ \\
\hline Attitude on risk of using OFDS & 0.039 & 0.7 & $0.5-1.0$ & 0.788 & 1.0 & $0.7-1.3$ \\
\hline Attitude on benefit of using OFDS & 0.201 & 1.3 & $0.9-1.8$ & 0.094 & 1.4 & $0.9-2.0$ \\
\hline Attitude on barriers of using OFDS & 0.035 & 1.4 & $1.0-2.0$ & 0.702 & 1.1 & $0.8-1.5$ \\
\hline Attitude on feature of OFDS & 0.359 & 1.2 & $0.8-1.7$ & 0.041 & 1.4 & $1.0-2.0$ \\
\hline Satisfaction of using OFDS & $0.000 * *$ & 3.3 & $2.4-4.7$ & 0.034 & 1.5 & $1.0-2.1$ \\
\hline Perception about OFDS & 0.851 & 1.0 & $0.7-1.4$ & 0.737 & 0.9 & $0.7-1.3$ \\
\hline Environment and social influences & 0.397 & 1.2 & $0.8-1.6$ & $0.001 *$ & 1.8 & $1.3-2.5$ \\
\hline Preferences of OFDS choices & 0.144 & 1.3 & $0.9-1.8$ & $0.001 *$ & 1.7 & $1.2-2.4$ \\
\hline Knowledge about OFDS & 0.333 & 1.2 & $0.8-1.6$ & 0.155 & 1.3 & $0.9-1.8$
\end{tabular}

* p-value $<0.01 ;{ }^{* *}$-value $<0.00$

\section{Discussion}

Most participants in this study were women, which was in line with the research conducted in India and Indonesia, particularly in Palembang.(3,17) The study results require intervention, considering that several studies have indicated a significant relation between the frequencies in using OFO, is more dominant for women. $(1,13)$ Among all respondents, $63.1 \%$ were in the $20-29$ year age group. The same age group was also used in the measurements performed in Palembang (15-24 years) and India $(18-25$ years). $(17,18)$ This dominant age group is in accordance with the background of Depok, which is filled with students, even though the second-largest population of the participants in this study was employees.

We conducted a comprehensive assessment of the personal and socio-environmental factors influencing the frequency of OFO behavior and high-risk food consumption through OFDS. We found that satisfaction with OFDS acts as a cognitive predictor of the frequency of OFO behavior. Customer satisfaction is defined by Kotler as the mental state of a customer that results from the comparison between the customers' expectations before a purchase and performance perception after the purchase.(19) According to this definition, positive experiences of personal transactions with online services encourage the repetitive use of these services. As a subjective assessment of product performance based on prior expectations, customer satisfaction is also known as one of the essential objectives of building consumer relationships closely related to their experience.(20,21) When customers are satisfied with either the food (presentation, variety, taste, and healthy options) or e-service quality (the extent to which a website supports efficient and effective purchase and delivery of products and services), they are more likely to place repeated orders on the same service and recommend it to other potential customers.(22-24) However, given that most OFDS offer fast food, with expanded variety, portion size, energy, and sodium content over the last 30 years, this satisfaction value is closely related to increased intake of high-risk food, which can lead to various health impacts in the future.(25-27) 
In this study, the respondents with a high level of satisfaction made 3.8 times more frequent transactions. If customers feel satisfied with the transaction, their frequency of purchases will also increase. This is in line with some researchers who have studied the relations between customer satisfaction and the quality, security, and efficiency of billing systems and the design or appearance of an app. All of them indicated a strong association between consumer satisfaction and OFO frequency.(28-30) These findings agree with those obtained previously for the qualitative studies conducted in South Korea, which suggest that convenient foods are being preferred because of their short preparation time, taste, availability, accessibility, and tempting food environment (simplicity of obtaining the desired food whenever required even in the middle of the night just on a fingertip).(31)

Moreover, we found socio-environmental influences and preferences of OFDS as predictors of high-risk food consumption through OFDS. The domain of our inquiries was related to social aspects such as encouragement from family and friends, influencers, and advertisements. As for the environment, we inquired about access to vegetables and availability of restaurants and outlets to buy ready-to-eat food items. The easy availability of outlet facilities could be an encouraging factor, which makes it easier for respondents to order any food type. Young adults can easily obtain this information from social media and their peers. $(12,32)$ In addition, advertisements through TV programs, restaurant pages, and food are currently trending in the promotion of appetizing and tempting food, which unfortunately has poor nutritional value. $(21,33)$

Meanwhile, a significant relation has been established between choice of food type and OFO frequency and high-risk food consumption through OFDS. Rozin and Villmecke distinguished "preferences" and "likes" of food, where preference refers to the choice from what is available or the choice of one food item over another. In contrast, "liking" refers to hedonic affective reactions against food, which are usually directed by testimonies, recommendations, or rating scales. (34) A study conducted in China found an increase in the frequency of use of OFDS toward eating preferences for high-risk foods, which resulted in overnutrition and obesity.(35) In our study, most food items ordered by respondents within a month were fast food (Table 2). According to the National Institutes of Health $(\mathrm{NIH})$, the consumption of fast food, known as ready-to-eat food, has a higher possibility of killing humans prematurely compared to smoking.(36) Jiang et al. stated that a significant factor affecting the OFO frequency is high-risk foods, which are high in fat and sugar.(35,37,38)

\section{Conclusion}

This study presents the personal and socio-environmental factors that determine the frequency of OFO behavior and consumption of high-risk food through OFDS. Young Adults are very vulnerable to being influenced by social, environmental and advertising factors, including the influence of consuming food online. Order frequency, risk food order, and risk food consumption will increase if they get satisfaction in food order services. There is also a strong influence from the social-environmental factor and a significant preference of online food order choices.

However, this cross-sectional study cannot determine the cause-effect relation, and the findings cannot be generalized for the remaining young adult population in Depok City. Furthermore, advertising, as a strong influence on sharing the behavior of high-risk food consumption through OFDS, can be considered a channel to share healthy food consumption behavior with young adults. Regarding the future risk of NCD and the continuous program to prevent NCD, the government, through the Ministry of Health, needs to educate the community, particularly young adults, regarding the nutrition literacy level of healthy food consumption and high-risk food consumption.

\section{Abbreviations}

OFO : Online Food Ordering

OFDS : Online Food Delivery Services

NCD : Non-Communicable Diseases

NIH : National Institutes of Health

\section{Declarations}

\section{Ethics approval and consent to participate}

This study obtained ethical approval from The Research and Community Engagement Ethical Committee of Faculty of Public Health Universitas Indonesia number 597/UN2.F10.D11/PPM/00.02/2020. We took informed consent from all participants and ensured their anonymity.

\section{Consent for publication}

Not applicable. Does not contain any details, images, or videos relating to an individual person

\section{Availability of data and material}

The questionnaire was administered through a registered online survey platform named Alchemer (https://www.alchemer.com), formerly called SurveyGizmo. The data analysis was by using SPSS version 22 .

\section{Competing interests}

None. The authors declare no competing interests. 
The Directorate of Research and Community Engagement, Universitas Indonesia, funded this research with grant number BA1337/UN2.RST/PPM.00.03.01/2020.

\section{Authors' contributions}

EM lead and concepted this research, developed the methodology, wrote the original manuscript and also reviewed and edited the final manuscript. DA carried out the formal analysis, reviewed and edited the final manuscript. B comprehended the formal analysis and also reviewed and edited the final manuscript. NDR developed the methodology, participated in the formal analysis, wrote the original manuscript and also reviewed and edited the final manuscript. APM participated in the concept of the research, carried out the data curation, helped to draft the original manuscript and also reviewed and edited the final manuscript. YS wrote the original manuscript, reviewed and edited the final manuscript. MA participated in the formal analysis, carried out the data curation and helped to draft the original manuscript. RSZ carried out the data curation and helped to draft the original manuscript.

\section{Acknowledgements}

We want to acknowledge the contributions from the Directorate of Research and Community Engagement, Universitas Indonesia, for funding this study.

\section{References}

1. Iyer B. A study of consumer behavior towards food ordering through mobile apps. International Journal of Advance Research, Ideas and Innovations in Technology (IJARIIT) [Internet]. 2019;5(4):360-366. Available from: https://pdfs.semanticscholar.org/74b2/c976d9b88259de1bfe2cdd439e903f45ce44.pdf

2. Chen HS, Liang CH, Liao SY, Kuo HY. Consumer attitudes and purchase intentions toward food delivery platform services. Sustainability (Switzerland). 2020;12(23):1-18.

3. Apurva D, Vashishtha DA. Study on consumer perception towards online food ordering and delivery services. International Journal of Research and Analytical Reviews (IJRAR) [Internet]. 2020;7(2):594-693. Available from: https://www.ijrar.org/download1.php?file=IJRAR2004217.pdf

4. Hasanah HLA, Aritonang E, Zulhaida Lubis. The relationship between type and frequency of online food ordering with obesity in students of Medan Area University. Britain International of Exact Sciences (BloEx) Journal. 2020;2(1):29-34.

5. Liu H. Factors positively influencing customer satisfaction of online food delivery services of customers in Bangkok and its vicinity. Bangkok University; 2019. Available from: http://dspace.bu.ac.th/bitstream/123456789/4406/1/Haiyang Liu.pdf

6. Aprilianti I, Amanta F. Promoting food safety in Indonesia's online food delivery services. Jakarta: Center for Indonesian Policy Studies, 2020. 36 p. Policy Paper No. 28. Available from: https://repository.cips-indonesia.org/media/324008-promoting-food-safety-in-indonesias-onli-0d578aa1.pdf

7. Lee SW, Sung HJ, Jeon HM. Determinants of continuous intention on food delivery apps: Extending UTAUT2 with information quality. Sustainability (Switzerland). 2019;11(11): 3141.

8. Talabpetch MN. Consumer Behavior and Purchase Decision Towards Lineman (on Demand Food Delivery) in Bangkok [Internet]. 2017. Available from: http://ethesisarchive.library.tu.ac.th/thesis/2017/TU_2017_5902040756_8453_6806.pdf

9. Jayani DH. Pemesanan Makanan secara Online Makin Digemari [Internet]. 2019. Available from: https://databoks.katadata.co.id/datapublish/2019/09/26/pemesanan-makanan-secara-online-makin-digemari (Indonesia)

10. Neilsen Company. Digital Consumers Show Positive Growth Trends. 2020. Available from: https://www.nielsen.com/id/en/press-releases/2020/digitalconsumers-show-positive-growth-trends/

11. BPS. Statistik E-Commerce 2020 [Internet]. Jakarta. 2020. Available from: https://www.bps.go.id/publication/download.html? nrbvfeve=MjU0ODQxN2RkYzZkYWI4MjQ3NTUzMTI0\&xzmn=aHR0cHM6Ly93d3cuYnBzLmdvLmlkL3B1YmxpY2F0aW9uLzIwMjAvMTIvMjQvMjU0ODQxN2RkY

12. Li C, Mirosa M, Bremer P. Review of online food delivery platforms and their impacts on sustainability. Sustainability (Switzerland). 2020;12(14):1-17.

13. Shepherd J, Harden A, Rees R, et al. Young people and healthy eating: A systematic review of research on barriers and facilitators. Health Education Research. 2006;21(2):239-257.

14. Verstraeten R, Leroy JL, Pieniak Z, et al. Individual and environmental factors influencing adolescents' dietary behavior in low- and middle-income settings. PLOS ONE. 2016;11(7):1-15.

15. Nicklas TA, Baranowski T, Cullen KW, Berenson G. Eating patterns, dietary quality and obesity. Journal of the American College of Nutrition [Internet]. 2001;20(6):599-608. Available from: https://pubmed.ncbi.nlm.nih.gov/11771675/

16. Popovic I, Bossink BAG, van der Sijde PC. Factors influencing consumers' decision to purchase food in environmentally friendly packaging: What do we know and where do we go from here? Sustainability (Switzerland). 2019;11(24):1-22.

17. Story M, Kaphingst KM, Robinson-O'Brien R, Glanz K. Creating healthy food and eating environments: policy and environmental approaches. Annual Review of Public Health. 2008;29:253-272. 
18. Bandura A. Social cognitive theory of personality. Handbook of Personality. 1999;2:154-196.

19. lisnawati RA, Yunita D. Consumer Decision on Online Food Delivery. Proceedings of the 5th Sriwijaya Economics, Accounting, and Business Conference (SEABC 2019) 2020 May 23. Atlantis Press; Available from: https://doi.org/10.2991/aebmr.k.200520.069

20. Beliya A, Kujur R, Verma M, et al. Satisfaction of consumers by using online food services. International Journal of Humanities and Social Sciences (IJHSS). 2019;8(4):35-44.

21. Suhartanto D, Brien A, Sumarjan N, Wibisono N. Examining attraction loyalty formation in creative tourism. International Journal of Quality and Service Sciences. 2018;10(2):163-175.

22. Ganapathi P, Abu-Shanab EA. Customer satisfaction with online food ordering portals in Qatar. International Journal of E-Services and Mobile Applications. 2020;12(1):57-79.

23. ZeithamI VA, Parasuraman A, Malhotra A. An Empirical Examination of the Service Quality-Value-Loyalty Chain in an Electronic Channel. Journal of Service Science and Management. Journal of Service Science and Management. Working Paper, University of North Carolina, Chapel Hill. 2002.

24. Al Amin M, Arefin MS, Sultana N, Islam MR, Jahan I, Akhtar A. Evaluating the customers' dining attitudes, e-satisfaction and continuance intention toward mobile food ordering apps (MFOAs): Evidence from Bangladesh. European Journal of Management and Business Economics. 2020;ahead-of-p(aheadof-print).

25. Suhartanto D, Helmi AM, Tan KH, Sjahroeddin F, Kusdibyo L. Loyalty toward online food delivery service: the role of e-service quality and food quality. Journal of Foodservice Business Research [Internet]. 2019;22(1):81-97. Available from: https://doi.org/10.1080/15378020.2018.1546076

26. McCrory MA, Harbaugh AG, Appeadu S, Roberts SB. Fast-food offerings in the united states in 1986, 1991, and 2016 show large increases in food variety, portion size, dietary energy, and selected micronutrients. Journal of the Academy of Nutrition and Dietetics. 2019;119(6):923-933.

27. Fuhrman J. The hidden dangers of fast and processed food*. American Journal of Lifestyle Medicine. 2018;12(5):375-381.

28. Stephens J, Miller H, Militello L. Food delivery apps and the negative health impacts for Americans. Frontiers in Nutrition. 2020;7:1-2.

29. Paz-Pacheco E. Trust and commitment. Journal of the ASEAN Federation of Endocrine Societies. 2016;31:3.

30. Liu Y, Li H, Hu F. Website attributes in urging online impulse purchase: An empirical investigation on consumer perceptions. Decision Support Systems [Internet]. 2013;55(3):829-837. Available from: http://dx.doi.org/10.1016/j.dss.2013.04.001

31. Belanche D, Flavián M, Pérez-Rueda A. Mobile apps use and WOM in Belanche, D., Flavián, M., \& Pérez-Rueda, A. (2020). Mobile apps use and WOM in the food delivery sector: The role of planned behavior, perceived security and customer lifestyle compatibility. Sustainability (Switzerland) [Internet]. 2020;12(10). Available from: https://www.mdpi.com/2071-1050/12/10/4275/pdf

32. Yoon NH, Yoo S, Kwon S. Influence of highly accessible urban food environment on weight management: A qualitative study in Seoul. International Journal of Environmental Research and Public Health. 2018;15(4):755.

33. Klassen KM, Douglass $\mathrm{CH}$, Brennan L, Truby H, Lim MSC. Social media use for nutrition outcomes in young adults: A mixed-methods systematic review. International Journal of Behavioral Nutrition and Physical Activity 2018;15(1):70. doi: 10.1186/s12966-018-0696-y.

34. Fast Food Nutrition. Fast Food Restaurants Nutrition Facts: KFC Nutrition Facts [Internet]. [cited 2021 Mar 3]. Available from: https://fastfoodnutrition.org/kfc

35. Ganapathi P, Abu-Shanab E. Customer satisfaction with online food ordering portals in Qatar. International Journal of E-Services and Mobile Applications. 2019;12:57-79.

36. Rozin P, Vollmecke TA. Food likes and dislikes. Annual Review of Nutrition [Internet]. 1986;6(1):433-456. Available from: https://pdfs.semanticscholar.org/0f03/bba0ed1905d58c077c6e9d2a07df618298f0.pdf?_ga=2.138986099.118793288.1614635302922968449.1614635302

37. Jiang Y, Wang J, Wu S, et al. Association between take-out food consumption and obesity among Chinese university students: A cross-sectional study. International Journal of Environmental Research and Public Health. 2019;16(6):1071.

38. Murray C, Atkinson C, Bhalla K, Birbeck G, Burstein R, Chou D. The state of US health, 1990-2010: burden of diseases, injuries, and risk factors. JAMA Journal of the American Medical Association [Internet]. 2013;310(6):591-608. Available from:

http://jama.jamanetwork.com/data/Journals/JAMA/927436/joi130037.pdf\%5Cnhttp://ovidsp.ovid.com/ovidweb.cgi?

$\mathrm{T}=\mathrm{JS} \& \mathrm{PAGE}=$ reference\&D$=$ emed11\&NEWS=N\&AN=2013503627\%5Cnhttp://ovidsp.ovid.com/ovidweb.cgi?

$T=J S \& P A G E=$ reference\& $=$ medl\&NEWS $=N \& A N=23842577$

39. Sijtsema S, Linnemann A, Van Gaasbeek T, Dagevos H, Jongen W. Variables influencing food perception reviewed for consumer-oriented product development. Critical Reviews in Food Science and Nutrition. 2002;42(6):565-581. 
40. Drewnowski A, Henderson S, Levine A, Hann C. Taste and food preferences as predictors of dietary practices in young women. Public Health Nutrition. 2000;2:513-519. 